\title{
Current State and Trend of Waste and Recycling in Japan
}

\section{Takashi Amemiya*}

Department of Products Engineering and Environmental Management, Nippon Institute of Technology, Miyashiro, Saitama-345-8501, Japan

\section{Abstract}

This report statistically introduces the current state and recent trends regarding resource circulation, industrial and municipal waste and recycling in Japan. Also recycling systems for home appliance waste and ELV (end of life vehicle) waste are discussed.

The ratio of the total amount of recirculated resources in Japan to the national total material input was $15.8 \%$ in the 2014 fiscal year. This ratio has been increasing continuously over the past 20 years mainly due to steady progress in the industrial waste recycling and to gradual shrinkage of the domestic natural resource input.

Japanese total waste volume in the 2014 fiscal year was $437 \mathrm{Mt}$ (million tons), with $89.9 \%$ industrial waste and $10.1 \%$ municipal waste. The amount of recirculated resources derived from this waste was $50.6 \%$ of the total waste volume. The final landfill amount of the total waste was only $3.4 \%$. When comparing the breakdown of waste treatment with the three major EU countries, Germany, France and the UK, the ratio of recirculated resource was not significantly different. But a characteristic feature of Japan was that the ratio of reduction amount by dewater and drying was very large, and the ratios of backfilling and final disposal amounts are considerably smaller.

With regard to the recycling of major used products disposed of by consumers in Japan, the current status of home appliance recycling and ELV recycling are discussed. With an individual recycling system constituted in each product area, manufacturers and distributors are obliged to implement recycling, and consumers are charged with recycling costs. At the moment these are successful models that are promoting recycling with high steady recycling rates.

\section{Publication History:}

Received: May 24, 2018

Accepted: August 11, 2018

Published: Aigust 13, 2018

\section{Keywords:}

Recycling, Municipal waste, Industrial waste, Home appliance recycling, ELV, ASR

\section{Introduction}

In Japan, the social and industrial structure based on resourceconsuming economies with mass production, mass consumption, and mass disposal continued until the early 1990s, when its economic growth began sharply to slow down and entered a period of stagnation. Since the United Nations Environment Summit held in Brazil in 1992, Japanese society has gradually shifted to a sustainable economic structure that responds to various environmental problems. Furthermore, the Basic Act on Establishing a Sound Material-Cycle Society [1] aiming to reform Japan to a resource recycling society was enacted in 2000, from which various nationwide efforts of resource recycling, control of waste discharges, and reduction of final disposal amount have been promoted throughout the country.

As to the main consumer products for individuals in the high economic growth era, automobiles and large household electric appliances were symbols of wealth, in terms of personal consumption. But the mass disposal of these products after their use brought about serious environmental problems which became a large concern in the latter half of the 1990s. For the purpose of solving these environmental issues and establishing effective resource recycling systems, a number of product-base individual recycling laws (being positioned as subordinate laws of the Basic Act on Establishing a Sound MaterialCycle Society) came into force. Under these laws obligations and burdens between product manufacturers and consumers were clarified (that is, manufacturers are in charge of collection and proper recycling, and consumers are in charge of recycle costs). Thereafter, these product recycling systems were accepted by society and continued operation since then.
In this paper, the overview of resource circulation, waste and recycling in Japan is reported based on statistical data, and some current issues are discussed. It is considered that the background and the present circumstances as described above include both common and different viewpoints when compared with other countries. It is the author's intention to show that these pieces of information are more or less usable for analysis and discussion of such field in other countries.

\section{Resource Recycle Rate in Japan}

The latest statistics data on total material flow in Japan indicating whole resource inputs, consumptions and recycled amount is published for the 2014 fiscal year. (Hereinafter, 2014 FY. The fiscal year in Japan starts from April.).

The summary of material flow is shown in Figure 1 [2]. According to this chart, the total material input (that is, the sum of imported and domestic resources and recycled amount) in 2014FY was 1,649 Mt (million tons) and the domestic recycled amount was $261 \mathrm{Mt}$. The ratio of the recycled amount to the total material input (hereinafter referred to as RRR, or Resource Recycle Rate) was $15.8 \%$. Figure 2 shows the trend of the RRR over the 20 years from $1994 \mathrm{FY}$ [3]. The

"Corresponding Author: Prof. Takashi Amemiya, Department of Products Engineering and Environmental Management, Nippon Institute of Technology, Miyashiro, Saitama-345-8501, Japan; E-mail: amemiya@nit.ac.jp

Citation: Amemiya T (2018) Current State and Trend of Waste and Recycling in Japan. Int J Earth Environ Sci 3: 155. doi: https://doi.org/10.15344/2456$351 X / 2018 / 155$

Copyright: @ 2018 Amemiya. This is an open-access article distributed under the terms of the Creative Commons Attribution License, which permits unrestricted use, distribution, and reproduction in any medium, provided the original author and source are credited. 
Citation: Amemiya T (2018) Current State and Trend of Waste and Recycling in Japan. Int J Earth Environ Sci 3: 155. doi: https://doi.org/10.15344/2456$351 \mathrm{X} / 2018 / 155$

Page 2 of 11

RRR was $8.2 \%$ in $1994 \mathrm{FY}$, but continued to rise consistently and has become almost twice the amount in 2014 FY. Figure 2 also shows the trend of the ratio of final disposal (landfill) amount to the total material input. This final disposal ratio, which was $4.8 \%$ in 1994 FY, decreased consistently and has fallen to only $1.1 \%$ in 2014 FY. Although this small number can be said to be a desirable result, since the final disposal amount is still $15 \mathrm{Mt}$, further efforts in reduction are considered necessary for a sustainable recycling-oriented society.

According to Figure 2, it appears as if Japan's national effort to increase resource circulation and to promote the recycling of waste has had great results. But actually it is necessary to consider the fact that the total material input (that is, the denominator of the RRR) has decreased largely in the past 20 years and therefore the RRR has risen in the calculation.

Figure 3 shows the trend of total input of natural resources and its breakdown (that is, imported and domestically produced) [3]. In Figure 3, the amount of the total input of natural resources has decreased by about $30 \%$ from $1994 \mathrm{FY}$ to $2014 \mathrm{FY}$, mainly due to the fact that the domestic resource production is reduced by about $50 \%$. Japan relies on imports for most of its energy and mineral resources, while limestone, sand, rock, gravel and other nonmetallic minerals account for the majority of the natural resources produced domestically. These domestic natural resources are used as concrete components and as materials for civil works such as roads and building construction. Annual statistics of concrete shipment volume have also been reported whereby shipments of concrete have almost halved in the last 20 years [4], which means that the infrastructure construction in Japan continued to shrink during this period. In this way, the drastic reduction of domestic mineral resource use caused a decrease in Japan's total material input, resulting in an increase in the numerical calculation of RRR.

A trend over the decade since $2004 \mathrm{FY}$ of the total recycled amount in Japan's material flow is shown in Figure 4 [5]. This recycled amount is defined as the sum of 'usable materials derived from waste', and 'valued recyclable resources'. The latter consists of valued materials (that is, not waste) discharged from home and byproducts brought by industrial activities. In $2014 \mathrm{FY}$, out of the $261 \mathrm{Mt}$ of the recycled amount, the 'usable materials derived from waste' accounts for 59\%, and the 'valued recyclable resources' accounts for $41 \%$. As shown in Figure 4, the amount of the 'usable materials derived from waste' has not greatly changed over the decade since $2004 \mathrm{FY}$, while the amount

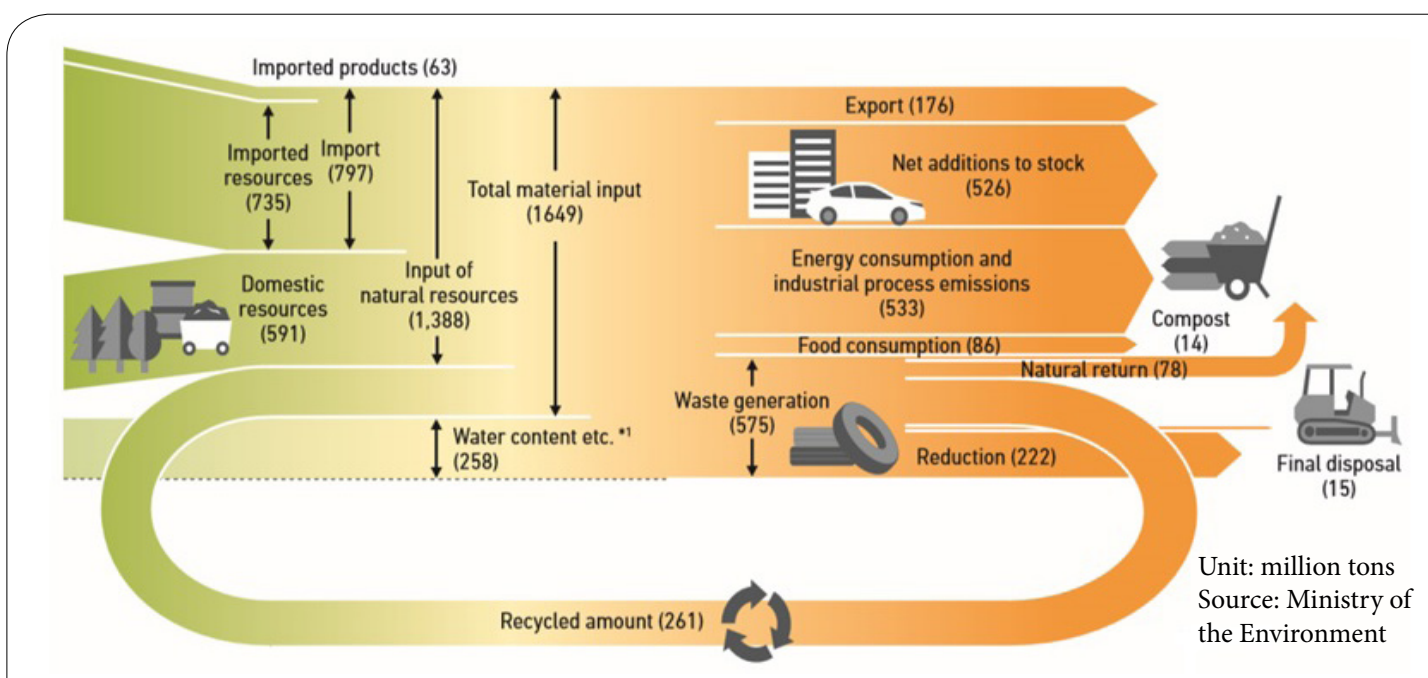

Figure 1: Material flow in Japan (2014FY) [2].

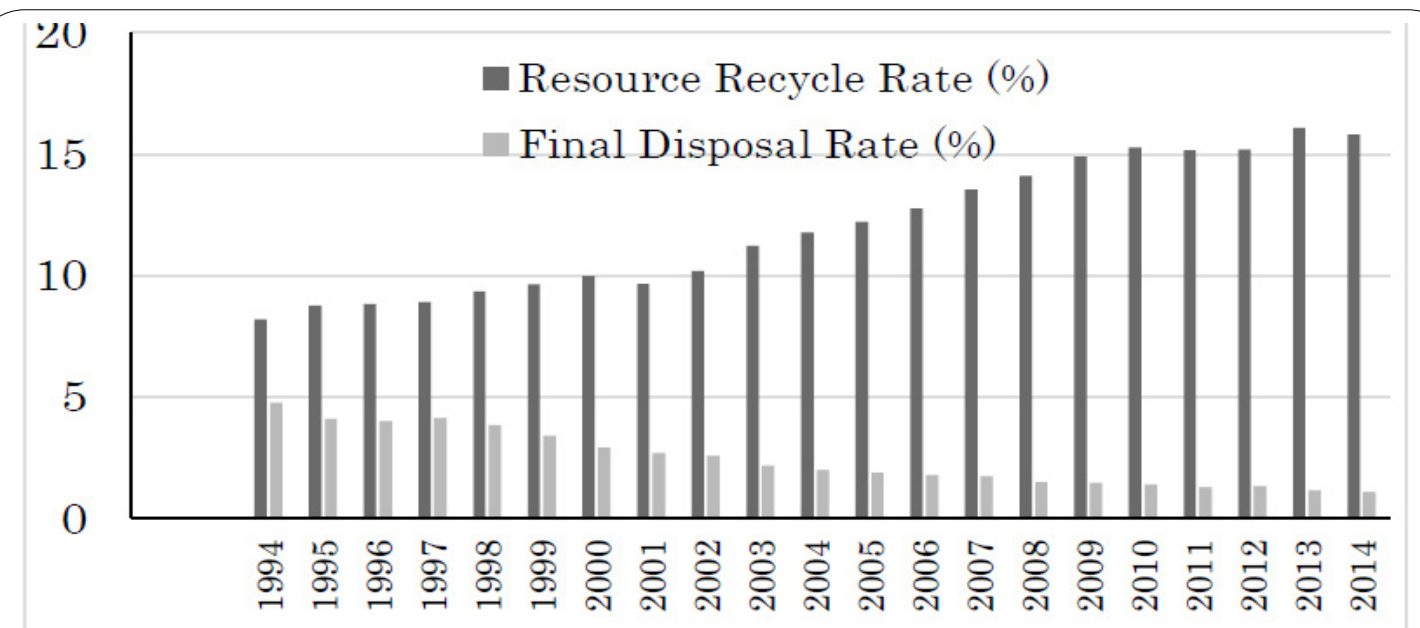

Figure 2: Trend of RRR (resource recycle rate) and final disposal rate [3]. 
Citation: Amemiya T (2018) Current State and Trend of Waste and Recycling in Japan. Int J Earth Environ Sci 3: 155. doi: https://doi.org/10.15344/2456$351 \mathrm{X} / 2018 / 155$

Page 3 of 11

of the 'valued recyclable resources' has gradually increased. Figure 5 shows the breakdown of the 'valued recyclable resources' [5]. As illustrated from this figure, the main elements of the increase are metal resources (mainly recovered metals such as scrap iron) and non-metallic mineral resources (mainly slag derived from the steel manufacturing process).
From Figures 2, 3 and 4, it is clarified that the main factor contributing to the long-term improvement of RRR is not the increase of 'usable materials derived from waste', but rather it is the decrease of the total material input; this is the denominator for calculating RRR. Also Figures 4 and 5 show that the growth of industrial 'valued recycling resources' (scrap iron and slag) is another major factor of increasing RRR.
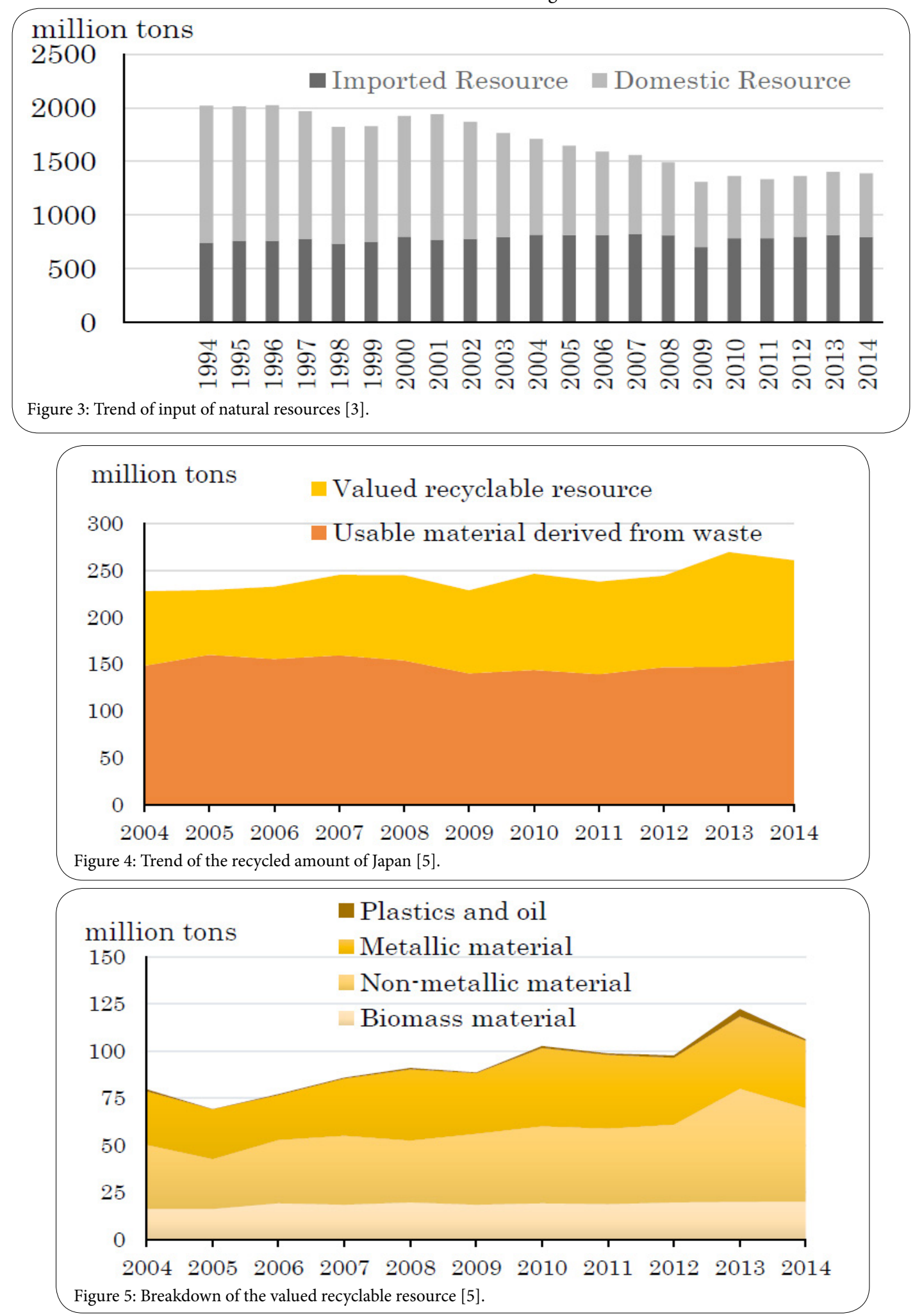
Citation: Amemiya T (2018) Current State and Trend of Waste and Recycling in Japan. Int J Earth Environ Sci 3: 155. doi: https://oi.org/10.15344/2456$351 \mathrm{X} / 2018 / 155$

Page 4 of 11

\section{Amount of Waste in Japan}

The amount of waste in Japan consists of industrial waste (discarded from industrial activities) and municipal waste (discarded from homes, small stores and offices).

Figure 6 shows the trend of the total waste amount discarded with its breakdown and the final disposal amount over the past 20 years [5]. The total waste amount tends to decline somewhat, but there is no significant change during 20 years. The proportion of municipal waste on the whole has also been largely unchanged at around $10 \%$. On the other hand, the final disposal volume has been steadily decreasing. The total waste amount in $2014 \mathrm{FY}$ was $437 \mathrm{Mt}$, of which $393 \mathrm{Mt}$ came from industrial waste and $44 \mathrm{Mt}$ from municipal waste. The final disposal amount was $14.8 \mathrm{Mt}$.

Figure 7 is the same period chart indicating the nominal GDP of Japan and the annual amount of industrial waste [6]. According to this figure, since $1997 \mathrm{FY}$, the trend of change in the nominal GDP and the trend of change in the industrial waste amount are very similar. It suggests that there has been a strong correlation between both factors and that economically created value in Japan is still strongly dependent on values accompanying hardware production rather than intangible values.
The breakdown of waste in $2014 \mathrm{FY}$ is shown in Table 1 [7]. Of the total waste discarded amounting to $437 \mathrm{Mt}$, the largest amount is sludge, accounting for nearly $40 \%$. Three quarters is organic sludge (such as sewage sludge), and a quarter is inorganic sludge (water sludge, construction sludge, etc.). Since sludge has higher water content than other waste, dewatering, thickening and drying are the main methods for sludge treatment.

\section{Recycling of Waste}

Figure 8 shows the treatment situation of municipal waste and industrial waste in $2014 \mathrm{FY}$. The breakdown of $44 \mathrm{Mt}$ of municipal waste is; $31 \mathrm{Mt}$ is reduction, $9 \mathrm{Mt}$ is recycling, and $4 \mathrm{Mt}$ is final disposal. The breakdown of $393 \mathrm{Mt}$ of industrial waste is; $170 \mathrm{Mt}$ is reduction, $212 \mathrm{Mt}$ is recycling, and $10 \mathrm{Mt}$ is final disposal [7].

As for the waste volume reduction in particular, in the case of municipal waste, $98 \%$ of the reduction is done by incineration (including power generation). In contrast, $93 \%$ of the industrial waste reduction is done by a non-incineration process such as dewatering, thickening and drying.

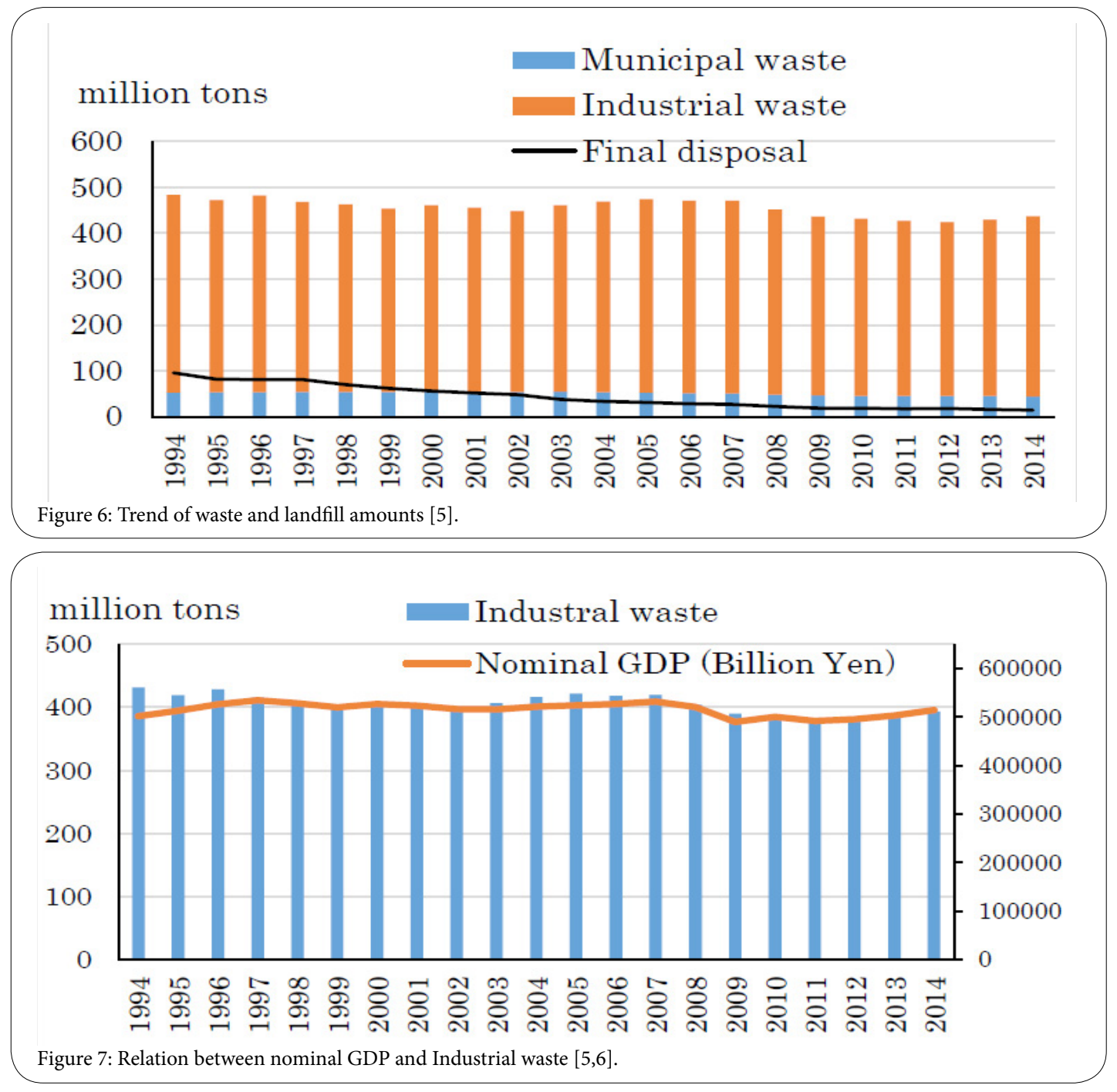


Citation: Amemiya T (2018) Current State and Trend of Waste and Recycling in Japan. Int J Earth Environ Sci 3: 155. doi: https://doi.org/10.15344/2456$351 \mathrm{X} / 2018 / 155$

The sum amount of recycling derived from municipal waste and industrial waste is $221 \mathrm{Mt}$, which corresponds to $50.6 \%$ of the total waste volume. Breakdown of this recycling is; $134 \mathrm{Mt}$ recycled as material, $67 \mathrm{Mt}$ returned to farmland as animal manure, and $21 \mathrm{Mt}$ used for land construction and soil amelioration. On the other hand, the sum amount of reduction is $201 \mathrm{Mt}$, which corresponds to $46.0 \%$ of the total waste volume. Its breakdown is, $43 \mathrm{Mt}$ by incineration loss including electricity generation, and $158 \mathrm{Mt}$ by the other weight loss. Summation of the amount 'recycled as material' and the amount 'used for land construction and soil amelioration' corresponds to the 'Usable material derived from waste' in Figure 4.

There are about 1,200 incineration facilities for municipal waste in Japan. Of these, 358 plants are generating electricity in 2014 FY, and the electric energy generated from municipal solid waste was 7,958 GWh [8]. In addition, the electric energy generated from industrial waste is reported to be $4,205 \mathrm{GWh}$ [9]. Since specific data on the amount of waste corresponding to these generated electricity is not published, the author estimated the waste input to the electric energy recovery as follows.
1. Municipal waste: Assumed the average power generation efficiency as $12.4 \%$ [8] and the average low heat value of waste as $8.8 \mathrm{MJ} / \mathrm{kg}$, whereby the waste input required to produce the electricity of 7,958 GWh is calculated to be $26.2 \mathrm{Mt}$.

2. Industrial waste: Assumed the waste to burn is mainly plastics with the average low heat value of $36 \mathrm{MJ} / \mathrm{kg}$, and the average power generation efficiency as $20 \%$, whereby the waste input required to produce the electricity of $4,205 \mathrm{GWh}$ is calculated to be $2.1 \mathrm{Mt}$.

From (1) and (2), the total amount of waste used for power generation (electric energy recovery) is estimated to be $28.3 \mathrm{Mt}$. By this incineration with electric energy recovery, the net reduced amount from waste is proportionally estimated to be $25 \mathrm{Mt}$. On the other hand, waste reduction by simple incineration without power generation is estimated to be $18 \mathrm{Mt}$.

Taking all the above discussion into consideration, the breakdown of total waste treatment is summarized in Table 2. In this table, out of 221 Mt of total recycling from waste, the $21 \mathrm{Mt}$ used for land construction

\begin{tabular}{|c|c|c|c|}
\hline & Volume (Million tons) & Breakdown & \\
\hline \multirow[t]{3}{*}{ Municipal waste } & \multirow{3}{*}{$44(10.1 \%)$} & House waste & $6.6 \%$ \\
\hline & & Office \& store waste & $3.0 \%$ \\
\hline & & Others & $0.6 \%$ \\
\hline \multirow[t]{5}{*}{ Industrial waste } & \multirow{5}{*}{$393(89.9 \%)$} & $\begin{array}{l}\text { Sludge } \\
\text { Organic sludge } \\
\text { Inorganic sludge }\end{array}$ & $\begin{array}{l}38.6 \% \\
(28.5 \%) \\
(10.1 \%)\end{array}$ \\
\hline & & Animal excrements & $18.6 \%$ \\
\hline & & Concrete/asphalt debris & $14.7 \%$ \\
\hline & & Dust & $4.0 \%$ \\
\hline & & Metal, plastics, wood, others & $13.9 \%$ \\
\hline Total & $437(100 \%)$ & & $100.0 \%$ \\
\hline
\end{tabular}

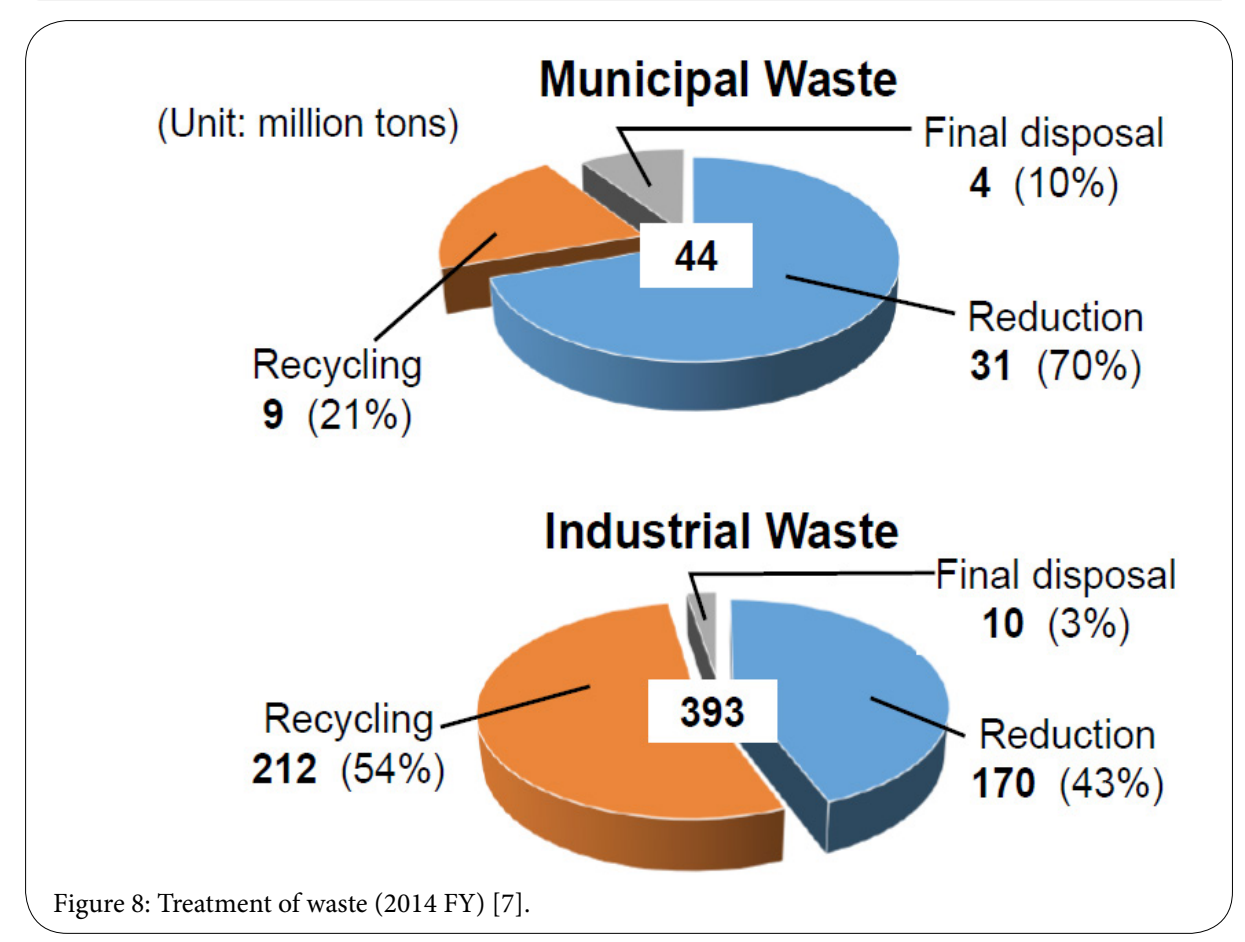


and soil amelioration is categorized as 'Backfilling' and separated from the category 'Recycling. The 'Recycling' (201 Mt) includes waste for material recycle $(134 \mathrm{Mt}$ ) and waste returned to farmland (namely 'Natural reduction', $67 \mathrm{Mt}$ ). The final landfill amount to the total waste is only $3.4 \%$. In the material recycle of $134 \mathrm{Mt}$ listed in Table 2, concrete/asphalt debris $63 \mathrm{Mt}$ is the largest proportion, followed by slag $13 \mathrm{Mt}$ and dust $13 \mathrm{Mt}$. They are crushed and processed, and used as roadbed materials and civil engineering materials. 'Reduction' as shown in Table 2, lists the lost weight of waste by means of various process. In detail, 'Energy recovery' $25 \mathrm{Mt}$ is the lost weight brought about by power generation, and 'Incineration' is $18 \mathrm{Mt}$ lost without power generation.

\begin{tabular}{|l|l|l|}
\hline \multicolumn{2}{|l|}{ million tons } & $\%$ \\
\hline Recycling & 201 & 45.9 \\
Material recycle & $(134)$ & $(30.6)$ \\
Natural reduction & $(67)$ & $(15.3)$ \\
\hline Reduction & 201 & 46.0 \\
Energy recovery & $(25)$ & $(5.7)$ \\
Incineration & $(18)$ & $(4.1)$ \\
Dewater, Thickening, Drying & $(158)$ & $(36.2)$ \\
\hline Backfilling & 21 & 4.7 \\
\hline Landfill & 15 & 3.4 \\
\hline Total waste amount & 437 & 100.0 \\
\hline
\end{tabular}

Column charts in Figure 9 show the waste treatment breakdown of Table 2 compared with waste treatment situations of major three EC countries (Germany, France and the UK) [10]. Also in Figure 9, waste discharge rate per nominal GDP of each country is plotted as a line graph [6]. In this figure, it is shown that the ratio of 'Recycling' of Japan is not much different from those of the other three countries, but 'Landfill' and 'Backfilling' amounts are considerably less compared to the other countries. On the other hand, the treatment for water reduction (dewater, thickening and drying) is very large. Because most sludge waste (both organic and inorganic) contains high moisture levels, a water reduction process is inevitably required, as Japan's climate has higher humidity so natural drying is generally not easy. On the other hand, data on European countries does not clearly indicate the amount of water reduction, but it is speculated that most of the sludge waste is treated as landfill or backfilling after reduced by natural drying, and the high water content organic sludge is mainly used for the biomass power generation.
As for the amount of waste used for energy recovery, in Japan it is smaller than in Germany, but larger than in France and the UK. However in Japan, the simple incineration amount is the largest. Accordingly, it seems there is room in Japan's case for increasing power generation using waste, however in reality it is difficult to realize because the majority of Japanese incineration facilities are small-scale so that it is not economically feasible to install power generation units (which are usually inefficient at small scale).

Comparison of the waste discharge rate per nominal GDP of each country in Figure 9 shows that Japan is smaller than Germany and France, but higher than the UK. The smaller this rate, the more preferable it is from the viewpoint of pursuing environmental efficient economy. If Japanese society shifts from the current quantity-valued mass production economy to a more quality-valued economy in the future, it is expected that the waste discharge rate per nominal GDP will be similar to the UK or even smaller.

\section{Home Appliance Recycling in Japan}

Under the Basic Act on Establishing a Sound Material-Cycle Society, which aims to build a sustainable recycling-oriented society, a reduction of waste discharge, and an increase of recycling from waste, is being promoted. As positioned under this basic act, six recycling laws relating to individual industry fields are in force as listed in Table 3. Especially related to the end-of-life of home appliances, two recycling laws are enforced, these are the Home Appliance Recycling Law and the Small Home Appliances Recycling Law.

The Home Appliance Recycling Law imposes obligation on manufacturers and import dealers to do collecting and recycling of four kinds of large home appliance categories (TVs, air conditioners, washing machines, and refrigerators) that are no longer usable in the home. Meanwhile, as consumers are the final users of home appliances, they are obliged to bear the 'recycling fee. The recycling fee is paid for the collection of home appliances and the amount differs depending on the type and capacity. The current fee level is between US $\$ 10$ to US $\$ 40$ per unit.

Figure 10 shows the trend of units in four categories recycled by manufacturers from $2001 \mathrm{FY}$ to $2016 \mathrm{FY}$ [11]. There was a peak during the three years around 2010, which was due to a sharp increase of TV units. This phenomena was brought about by a tentative expansion of TV replacement demand occurring along with the TV broadcasting

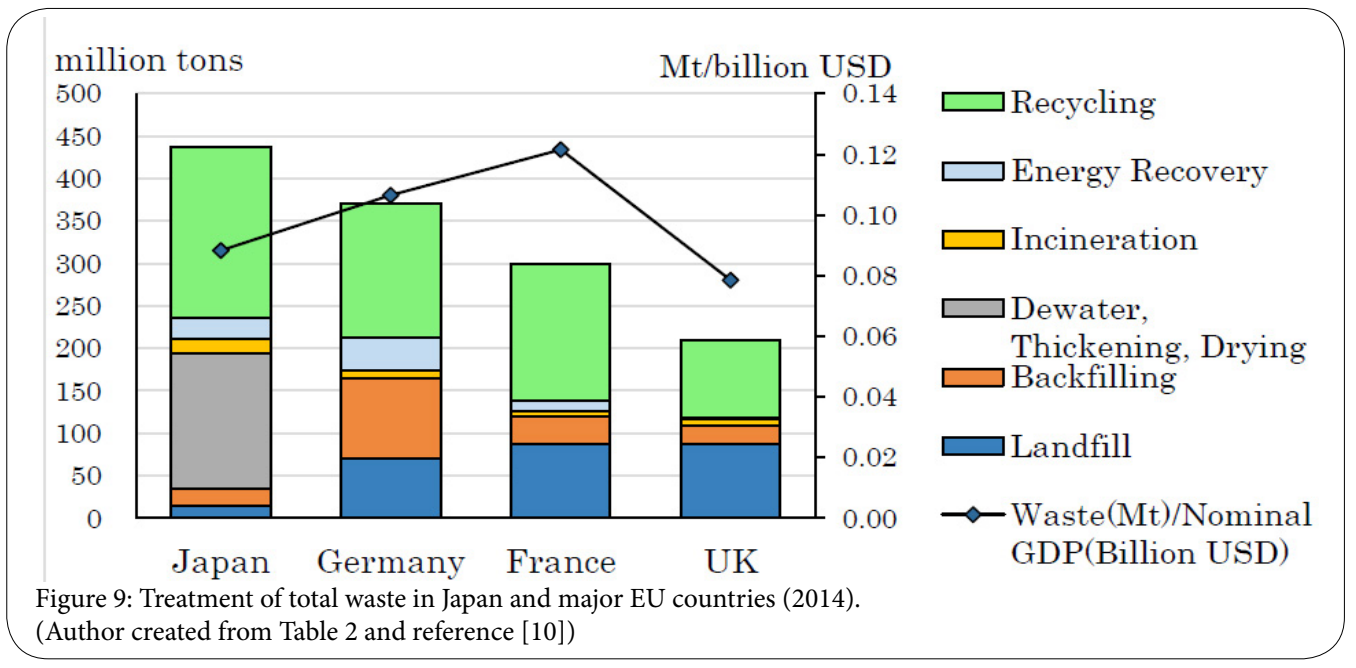


Citation: Amemiya T (2018) Current State and Trend of Waste and Recycling in Japan. Int J Earth Environ Sci 3: 155. doi: https://doi.org/10.15344/2456$351 \mathrm{X} / 2018 / 155$

Page 7 of 11

system transition in Japan from analog to digital in 2011. After that, the trend of recycled units dropped to the same level as before. In recent years about 11 million units per year are recycled in total. On the other hand, a statistical report on annual sales volume of new products (adding imports and subtracting exports) of household appliances in the four categories counts 24 million units of shipment respectively in $2014 \mathrm{FY}$ and $2015 \mathrm{FY}$, and about 25 million units in 2016 FY [12]. Because most of the new products are considered to be replacement of used appliances, the legally recycled number (that is, 11 million units) covers less than half of them. Therefore it is suspected that many used appliances are illegally processed or being transferred abroad as waste under the name of second hand goods. In the worst case, they are becoming 'high-tech trash' expanding environmental contamination to other countries.

Figure 11 [11] shows the trend of the recycle rate of used appliances received and recycled by manufacturers legally. The recycle rates of four model category excluding CRT TV have increased year by year. Accordingly, during the $2016 \mathrm{FY}$, they achieved very high numbers of $93 \%$ in air conditioners, $89 \%$ in flat panel televisions, $82 \%$ in refrigerators and freezers, and $90 \%$ in washing machines and dryers.
Only CRT TV shows a decline in the recycle rate since 2008 FY. This was due to the fact that TV production has shifted from the CRT type to a flat type worldwide. This brought about a sharp decline in demand for lead-containing glass, which was previously a stable application for recycled material from CRT TVs.

As for the various 'small' household electrical appliances used at home, other than the four major type categories, the Small Home Appliances Recycling Law enacted in 2012 charges municipalities to collect them from houses. Then certain recycling companies certified by the government can undertake the recycling treatment of the appliances after receiving them from the municipalities. The purpose of this law is to promote the collection of precious and/or rare metals from small household appliances, and to recirculate them as industrial raw metal resources. After three years from the enforcement of the law, the collection total in the $2016 \mathrm{FY}$ amounted to 68,000 tons nationwide [13], which is still only one tenth of the amount that was originally estimated.

Table 4 lists the comparison between the Home Appliance Recycling Law and the Small Appliances Recycling Law. Unlike the Home Appliance Recycling Law, the Small Appliances Recycling Law is unique in that it is not mandatory but municipalities are free

\begin{tabular}{|c|c|c|}
\hline Name of Law & Enacted Year & Target products \\
\hline $\begin{array}{l}\text { Basic Act on Establishing a Sound Material- } \\
\text { Cycle Society }\end{array}$ & 2000 & $\begin{array}{l}\text { Basic Framework Act: to ensure material-cycle society, control } \\
\text { consumption of natural resources, and reduce environmental load }\end{array}$ \\
\hline $\begin{array}{l}\text { Containers and Packaging } \\
\text { Recycling Law }\end{array}$ & 1995 & bottles, plastic bottles, plastic containers, packaging \\
\hline Home Appliance Recycling Law & 1998 & air conditioners, refrigerators, TVs, washing machines \\
\hline Food Recycling Law & 2000 & food waste \\
\hline Construction Materials Recycling Law & 2000 & wood, concrete, asphalt \\
\hline Law on Recycling of End-of-Life Vehicles & 2002 & automobiles (shredder dust, air bag, fluorocarbon gas) \\
\hline Small Home Appliances Recycling Law & 2012 & small electronic devices \\
\hline
\end{tabular}

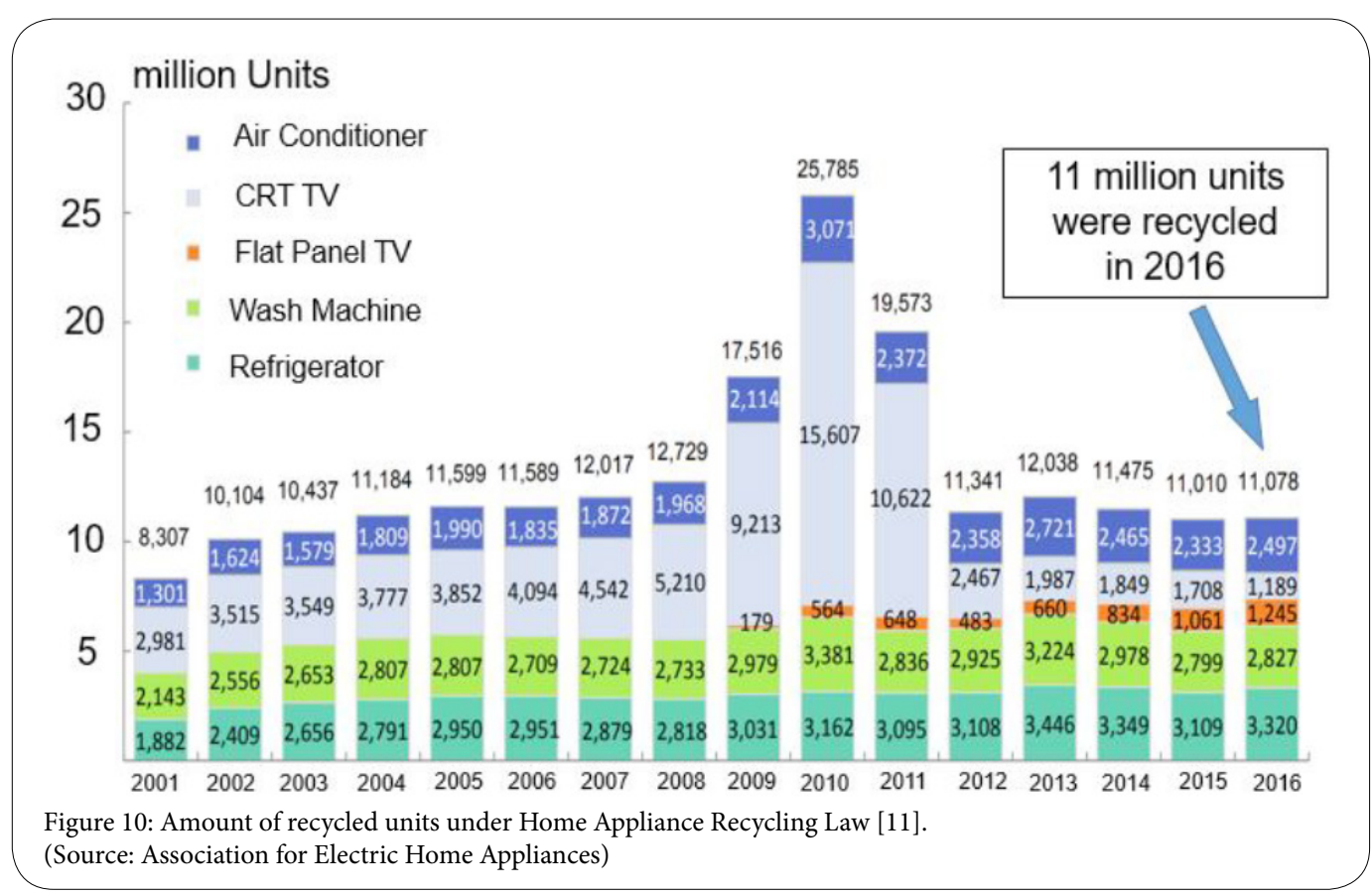


Citation: Amemiya T (2018) Current State and Trend of Waste and Recycling in Japan. Int J Earth Environ Sci 3: 155. doi: https://doi.org/10.15344/2456$351 \mathrm{X} / 2018 / 155$

Page 8 of 11

to choose whether or not to collect and recycle small household appliances. Also there is no cost obligation on consumers in the small appliances recycling system. If a municipality judges that the system is economically feasible, then the small appliances recycling system will be operated within the municipality area. Certified recyclers can purchase used appliances for their recycling business from municipalities or other organizations which collect appliances in place of the municipality. The number of municipalities implementing small home appliances recycling has been increasing year by year, reaching $70 \%$ of total 1,741 municipalities in $2016 \mathrm{FY}$.

One of the big problems of the small home appliances recycle system is that even in the municipalities where the system is being implemented, ordinary citizens are usually not made aware of the existence of the recycling system and they tend to store their small appliances in the house, even after they are worn out and outdated. The reason for this is that there is no cost levied on the citizen, and the law is encouraging compliance, but not enforcing it, so it is difficult to expect a large improvement in the collection rate and recycling rate. It will be necessary for municipalities to continue to strongly promote raising awareness of the importance of recycling to the citizens.

\section{Automobile Recycling in Japan}

The automobile is another example of a large-scale consumer products for individuals. Nowadays in Japan, the automobile recycling system is steadily being promoted and said to be one of the successful models of recycling. Before the enactment of the Law on Recycling of End-of-Life Vehicles in the latter half of the 1990s, the number of vehicles owned in Japan exceeded 70 million, and the number of end-of-life vehicles (here in after ELVs) exceeded 5 million annually. From the past, ELVs had been traded as a supply source of recycled materials and parts, so real recycling had been established as a business. For example, reusable engines and other parts were picked up by dismantlers, and scrap metals from the body were separated by shredders and sold to electric smelters for steel production. On the other hand, the shredder dust (ASR, or Automobile Shredder Residue) remained as a light dust after shredding, which was mainly composed of debris of plastics and harnesses accounting for $20 \%$ to $25 \%$ by weight of ELVs, and was of no recyclable value and was therefore disposed of in landfills as waste.

However, the rapid rise in cost of ASR disposal due to a tightening of landfill spaces and possible hazardous elements contained in ASR became a big problem at the time. The high ASR treating cost meant many shredder businesses became unprofitable and made it difficult for them to buy ELV bodies at an economical cost. This could have collapsed the conventional ELV recycling system totally. In addition, strict preventing of the release fluorocarbon gas from air conditioners was requested by law, and a safe way of processing air bag chemicals from ELVs was also strongly recommended by the manufactures themselves.

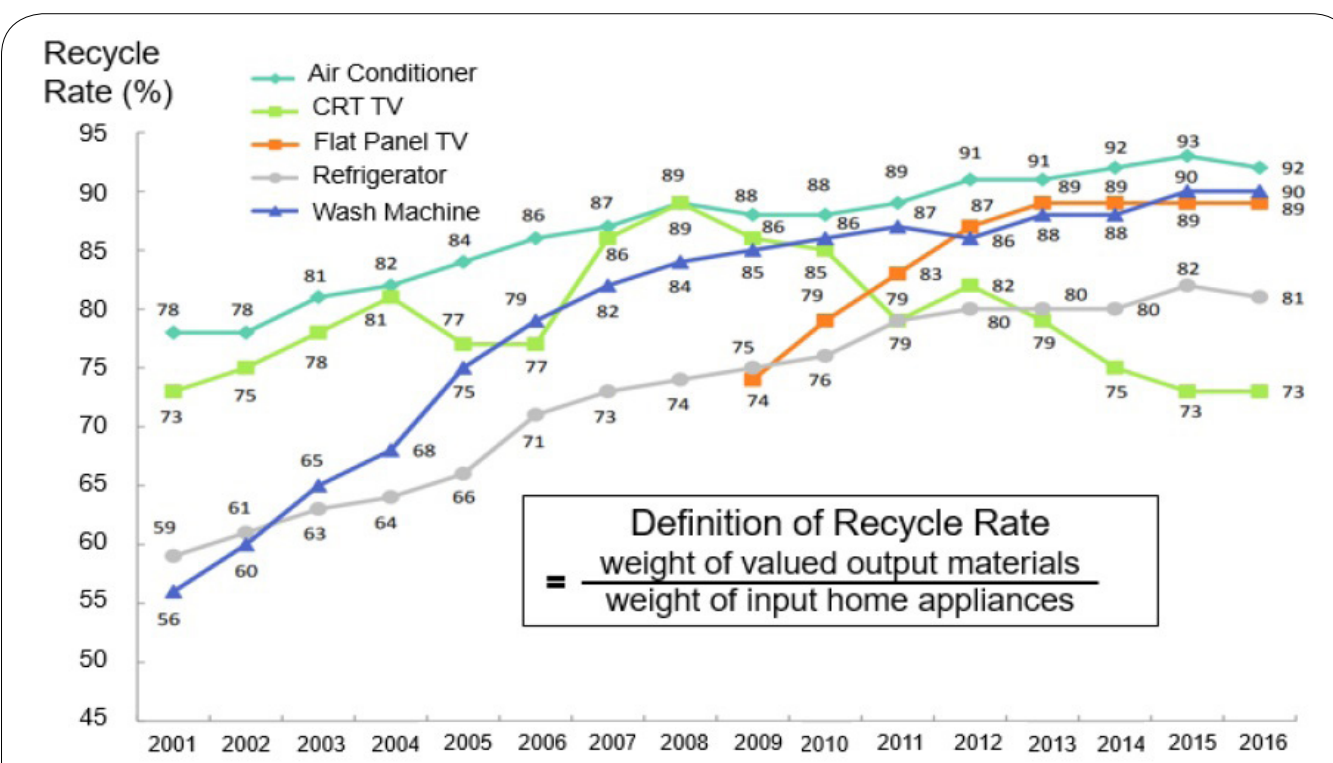

Figure 11: Trend of recycle rate of home appliances [11].

\begin{tabular}{|c|c|c|}
\hline & Home Appliance Recycling Law & Small Home Appliances Recycling Law \\
\hline Target Items & $\begin{array}{l}\text { four kinds of large home appliances (air } \\
\text { conditioner, TV, wash machine, refrigerator) }\end{array}$ & $\begin{array}{l}\text { small electric \& electronic appliances for use in daily life (such as PCs, } \\
\text { mobile phones, VTRs, DVDs, digital cameras, clocks and hair dryers) }\end{array}$ \\
\hline Collection & product manufacturers/importers & municipalities, authorized recyclers \\
\hline Recycling & product manufacturers/importers & authorized recyclers \\
\hline Cost burden & consumers & $\begin{array}{l}\text { No cost charge on consumers. } \\
\text { Profit from recycling may cover the system. }\end{array}$ \\
\hline Amount treated in $2016 \mathrm{FY}$ & 11 million units (approx. 400 thousand tons) & 68 thousand tons \\
\hline
\end{tabular}


Citation: Amemiya T (2018) Current State and Trend of Waste and Recycling in Japan. Int J Earth Environ Sci 3: 155. doi: https://doi.org/10.15344/2456$351 \mathrm{X} / 2018 / 155$

Page 9 of 11

In response to this situation, the Law on Recycling of End-of-Life Vehicles was enacted in 2002 and was fully enforced in 2005. Under this law automobile manufacturers and import distributors are required to properly collect, treat and recycle ASR, fluorocarbons, and air bags which are discharged from ELV dismantling and the shredding process. All costs for this recycling purpose is covered by a recycling fee paid by new car buyers. Currently, the recycling fee to be paid is about US\$100 to US $\$ 200$ per car depending on the type of cars. The recycling fee is collected from car buyers and received as a deposit by the Japan Automobile Recycling Promotion Center. From this deposit fund expenses are paid to automobile manufacturers or their contractors for treating ASR, fluorocarbons, and airbags.

Figure 12 shows the trends in the number of total registered cars, the number of new cars registered, and the number of ELVs in Japan [7]. From 2012, almost 5 million ELVs (deregistered) occurred annually. After subtracting the number exported as used cars, 65 to $70 \%$ of ELVs are disassembled and recycled via dismantler or shredder factories. Some proportion of ELVs are directly put into the electric furnace following the pressing process. Figure 13 shows that the trend of the total amount of ASR that was separated from disassembled ELVs is decreasing slightly in recent years [14].

The ratio of ASR amount compared to the whole vehicle weight is about $17 \%$ on average. The Law on Recycling of End-of-Life Vehicles imposes on facilities that process ASR that $40 \%$ or more of the ASR input amount must be recycled as material or recovered as energy on an equivalent weight basis. In reality, ASR recycling is carried out with a considerably higher value than this. In Figure 13 the trend of the overall recycling rate of ASR treatment (defined as the ratio excluding the residual of the treatment compared to the total input) is line plotted. The ASR recycling rate in 2016FY reached $97.9 \%$.

Figure14 shows the total material flow of LEV recycling in 2015 FY [7]. In that year, 3.17 million cars were received from end users to dismantlers through dealers and repair shops. Reusable parts and recyclable resources like oil and other materials were sold on the market and the car bodies (55 to $65 \%$ weight of ELVs) were shredded in shredder factories to produce scrap metals for sale to electric smelters. Separated ASR (17\% weight of ELVs) was treated for material recycling and/or energy recovery. As a result, $99 \%$ of the total weight of the ELVs was recycled as materials or energy. In order to achieve this, the ASR treating cost and the adequate disposal cost of fluorocarbons and airbags were covered by the recycle law.

As described above, in the Japanese automobile recycling system, the costs necessary for the treatment of ASR, fluorocarbons and airbags are covered by funds deposited by automobile buyers as a recycling fee. The amount of final disposal of ASR, which was once the root cause of the big problem of hazardous waste has drastically decreased, and the ASR recycling rate is at a high level in recent years. Now the ELV recycling is one of the most successful models of a recycling system in Japan.
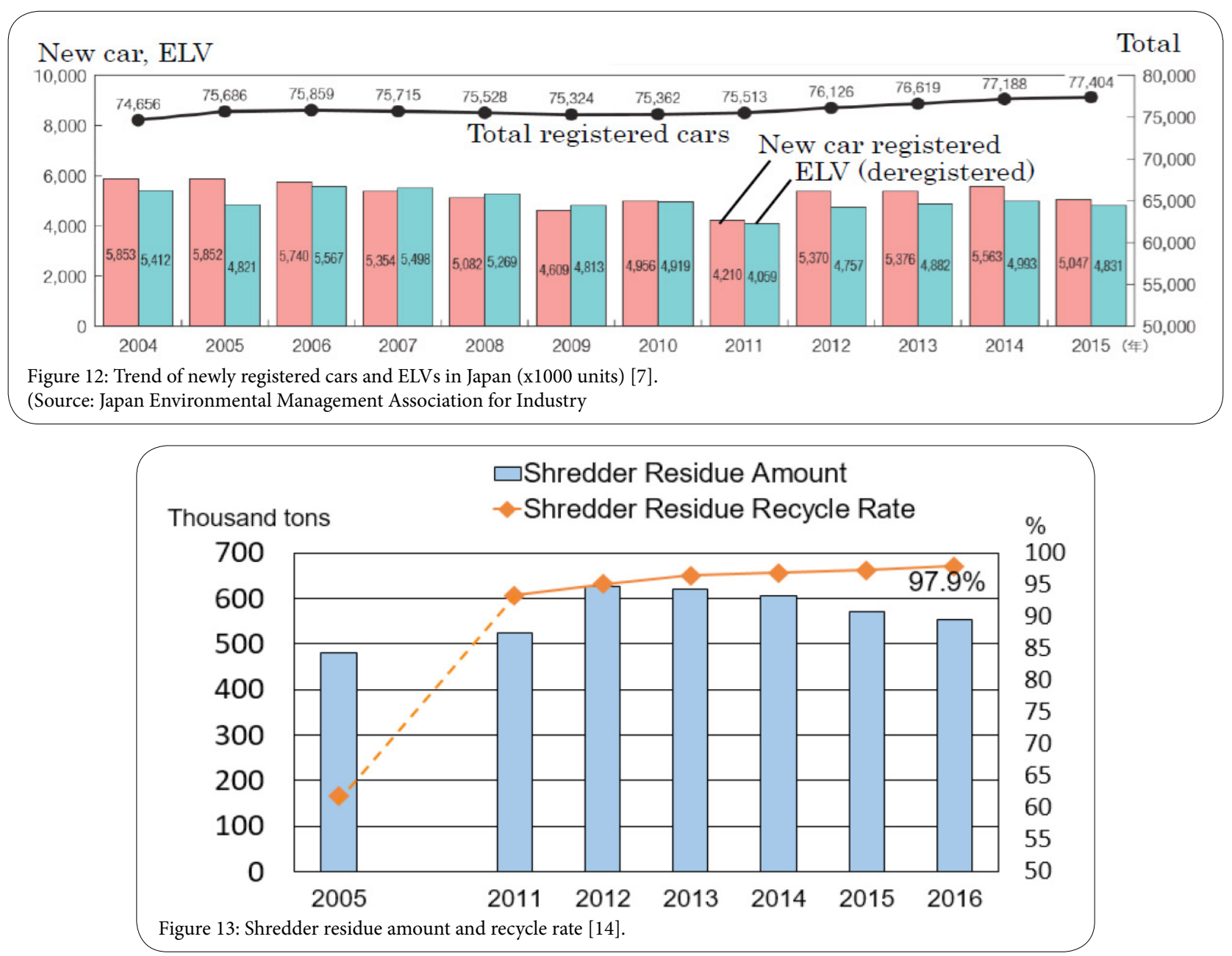


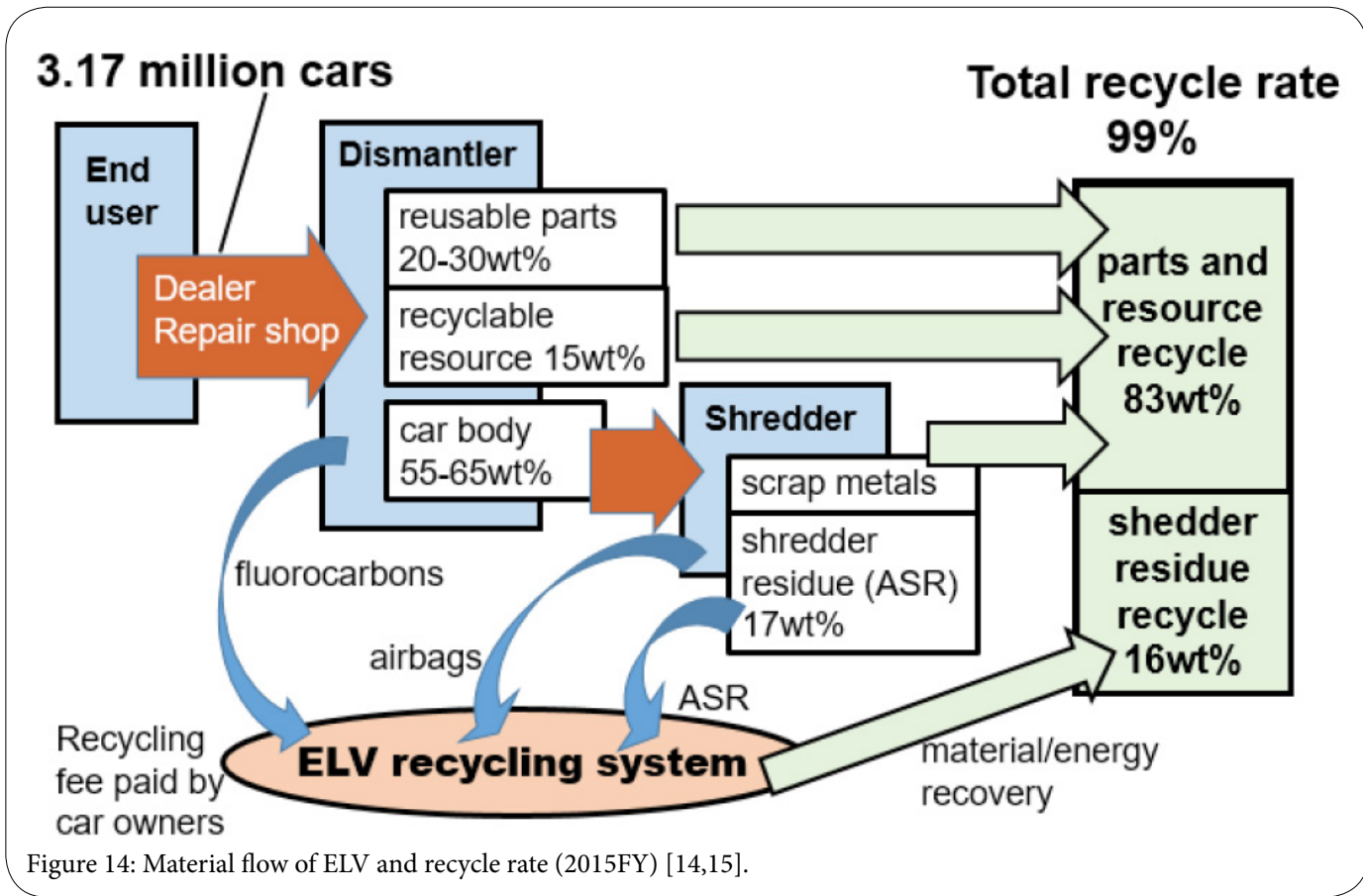

\section{Conclusion}

The domestic total of recirculated resources in Japan in 2014 FY accounted $261 \mathrm{Mt}$, and RRR, or Resource Recycle Rate, reached 16\%, which almost doubled in the 20 years from $1994 \mathrm{FY}$. Such improvement of the RRR is not a simple result of the effort to progress recycling in the industrial and the municipal waste sectors, but rather it is due to the fact that the domestic resources total (limestone, sand, rock, gravel and other minerals) has been reduced by about $50 \%$ in relation to the shrinkage of infrastructure construction in Japan during this period. The final disposal amount has continued to decrease over a long period, and the actual result in $2014 \mathrm{FY}$ has been reduced to $1 \%$ of the total input resource amount. Although this is a desirable result, the final disposal amount is still $15 \mathrm{Mt}$ and it is considered that a further reduction effort is needed for a sustainable recycling society.

The total amount of waste discharged in $2014 \mathrm{FY}$ was $437 \mathrm{Mt}$, 90\% of which was industrial waste and $10 \%$ was municipal waste. Over the past two decades, overall waste tends to decline somewhat, but there is no significant change. The trend of the amount of industrial waste seems to have a tight correlation with the trend of nominal GDP, suggesting that the Japanese economy is still based on physical value production rather than intangible value production. After the treatment of the waste, $50.6 \%$ of the total waste was recycled in some form, including material recycling, natural reduction and backfilling. When comparing the breakdown of waste treatment with the three major EU countries, the ratio of recycling is not much different, but landfill and backfilling are considerably smaller. On the other hand, the treatment for water reduction (dewatering, thickening and drying) is very large.

As examples of recycling of major used products disposed of by consumers in Japan, current status of home appliance recycling and ELV recycling were discussed. Under individual recycling laws enacted in each product area, manufacturers and distributors are obliged to implement recycling, and consumers are charged with recycling costs. At the moment these are successful models that are promoting recycling steadily with a high recycling rate. However, it is suspected a significant proportion of used home appliances are not collected in the formal recycle system and are supposed to be illegally processed or being transferred abroad under the name of second hand goods. This kind of illegal stream should be more strictly controlled to prevent expansion of environmental contamination and loss of recyclable resources nationwide.

\section{Competing Interests}

The authors declare that no competing interests exist.

\section{References}

1. Basic Act on Establishing a Sound Material-Cycle Society: Japanese Law Translation.

2. Annual report on the environment in Japan (2017) Ministry of the Environment.

3. Annual report on environmental statistics 2017, Chapter 4 (2017) Ministry of the Environment.

4. Shipping statistics of wet concrete (2017) National Wet Concrete Industry Association Federation.

5. Survey report on countermeasures for waste migration in the wide district and actual waste amount of recycling (2017) Ministry of the Environment.

6. World Economic Outlook Databases (2018) International Monetary Fund.

7. Recycle Data Book (2017) Japan Environmental Management Association for Industry.

8. Waste Treatment in Japan (2017) Ministry of the Environment.

9. Background of Waste Policy and Efforts to date (2016) Ministry of the Environment.

10. Eurostat Waste Statistics (2017) EU Eurostat.

11. Electric Home Appliance Recycle Annual Report (2017) Association for Electric Home Appliances.

12. Electric Home Appliances Industry Handbook (2017) Association for Electric Home Appliances.

13. Current Status of Enforcement of Small Home Appliance Recycling Law (2017) Ministry of the Environment. 
Citation: Amemiya T (2018) Current State and Trend of Waste and Recycling in Japan. Int J Earth Environ Sci 3: 155. doi: https://doi.org/10.15344/2456$351 \mathrm{X} / 2018 / 155$

Page 11 of 11

14. Current Status of Enforcement of Law on Recycling of End-of-Life Vehicles (2017) Ministry of Economy, Trade and Industry.

15. Annual Report on the Environment, the Sound Material-Cycle Society and Biodiversity in Japan (2017) Ministry of the Environment. 